\title{
Perception of Risk of Contracting HIV From Spouses Among Married Women In A Peri-Urban Community Of South West Nigeria
}

\author{
Oyedunni Sola Arulogun ${ }^{1}$, Olabisi Olutosin Obisesan ${ }^{1,2}$, Adeyimika Desmennu ${ }^{1}$ \\ ${ }^{1}$ Department of Health Promotion and Education, College of Medicine, University of Ibadan, Ibadan, Nigeria \\ ${ }^{2}$ Pharmacists Council of Nigeria, Olusegun Obasanjo House, $3^{\text {rd }}$ Floor, South-West wing, Yakubu Gowon Way, \\ Kaduna, Nigeria
}

\begin{abstract}
Perception of risk of contracting HIV from spouses was assessed among 390 married women selected from workplaces and households in Omi-Adio, a peri-urban Nigerian community. A pre-tested questionnaire containing a 14-point knowledge scale and focus group discussion guide were used to collect data. Quantitative data was analyzed using descriptive statistics, chi-square and ANOVA while the qualitative data analysis was by themes. Mean age of respondents was 30.2 \pm 2.9 years, $67.2 \%$ were in monogamous unions. Mean knowledge score was 7.3+2.9 and was significantly influenced by age and level of education $(p<0.05)$. Unprotected sex was perceived as the major route of infection (96.9\%), $95.0 \%$ believed that women could get HIV from their spouses and $10.0 \%$ of these perceived themselves to be at personal risk. Perceived risk factors for HIV infection from spouses included polygyny (77.2\%) and infidelity (51.5\%). Main preventive measures identified were mutual faithfulness (82.0\%), use of condom (8.5\%) and traditional methods (6.7\%). FGD respondents proffered satisfying one's spouse sexually so he doesn't indulge in extra-marital affairs and providing one's spouse with condoms as strategies for preventing HIV infection. Culturally sensitive health promotion programmes targeting couples aimed at increasing knowledge and uptake of effective preventive measures to reduce women's vulnerability are advocated.
\end{abstract}

Keywords - HIV/AIDS, HIV/AIDS knowledge, married women, preventive measures, risk perception

\section{Introduction}

The sub-Saharan Africa region has as at 2011, an estimated 23.5 million people living with HIV residing there representing $69 \%$ of the global HIV burden. In the same year, $92 \%$ of pregnant women living with HIV resided in sub-Saharan Africa. Women in sub-Saharan Africa remain disproportionately impacted by the HIV epidemic, accounting for 58\% of all people living with HIV in the region in 2011[1].

The AIDS epidemic has been found to have increasing prevalence among married women. A number of factors combine to put married women at risk; these include an inability to negotiate safe sex and a lack of communication between spouses, other factors include gender discrimination, gender based violence, abuse of human right, lack of economic empowerment, harmful cultural practices, a lack of sufficient knowledge about HIV/AIDS and low educational status [2,3]. Therefore being faithful as a means to prevent HIV only works if both partners are HIV negative when they begin the relationship and if both partners do not have sex outside of it [4]. This challenges the logic of preventive strategies that are based on messages of abstinence-until-marriage and monogamy for women and girls [5]. Some of the reasons for the high rates of HIV infection among married women are linked to the very reasons that some people marry; they want to have children and with no way to conceive and protect themselves from HIV at the same time they frequently put themselves at risk of HIV infection [6]. The majority of infected women are of child bearing age, opening the way for perinatal HIV transmission to their children on a large scale.

Reports from most countries of the world, especially countries in sub-Saharan Africa and Nigeria in particular showed that knowledge about HIV/AIDS among women is low compared to that of men. It is even lower in the rural areas due to a number of factors which include harmful cultural practices, economic disadvantage (due to limited access to economic opportunities) and limited access to health care and diminished social status [7]. In Nigeria only 23 percent of women have been documented to have comprehensive knowledge of the mode of HIV transmission and prevention [8]. Furthermore studies have found that women who are married at a younger age have less knowledge of HIV/AIDS than the unmarried, and are more likely to believe that they are at low-risk of becoming infected with HIV [9].

In addition, most HIV/AIDS prevention programmes have not focussed on the needs of married women and this has invariably contributed to the high incidence of HIV among this group. Preventive strategies that focus on abstinence and faithfulness in lieu of comprehensive evidence based prevention programmes are not 
adequate to protect a woman whose husband is unfaithful [10]. Also such strategies cannot protect a woman who does not perceive herself to be at risk of contracting HIV from her spouse. This study therefore set out to fill this gap by exploring married women's perception of risk towards contracting HIV from spouses.

\subsection{Study design}

\section{Methods}

This study was a cross sectional descriptive survey designed to determine married women's knowledge, perceptions and risks of contracting HIV from spouses in Omi-Adio community of Oyo State, southwest Nigeria.

\subsection{Study setting and study population}

Omi-Adio is a rural community in Ido Local Government Area (LGA) of Oyo state. It shares boundaries with Oluyole, Ibarapa, Akinyele, Ibadan North West, Ibadan South West LGAs in Oyo state and Odeda LGA of Ogun state. The people of Omi-Adio are predominantly Yorubas while farming is the major occupation in the community. Food crops and cash crops such as cassava, cocoa, palm oil and kola nut are produced in the community. There are two public secondary and several primary schools. The study site has one government owned health facility- a primary health care centre and several private health facilities. The study population was made up of women aged 15 to 45 years who are in a marriage relationship.

\subsection{Sampling procedure}

A multi-stage random sampling technique was used in selecting the 390 respondents for this study. Stage one consisted of the purposive selection of Omi-Adio community based on its strategic location as a busy peri-urban border community with huge human traffic of both men and women on economic activities from the city of Ibadan and neighbouring Abeokuta town. This was followed by the selection of 19 out of the 36 streets in the community through balloting. The third stage involved the systematic selection of households and workplaces and the final stage consisted of the selection of respondents from the households and the workplaces. In each selected household and workplace, the questionnaire was administered to a married woman selected at random.

\subsection{Instrument for data collection and process of data collection}

Both qualitative and quantitative methods of data collection were employed. The qualitative instrument was a focus group discussion guide which explored the perceptions of risk of married women towards contracting HIV from their spouses. The quantitative instrument was a 37-item questionnaire which collected information on respondents' socio-demographic characteristics, knowledge of HIV/AIDS, perceptions about HIV and perceived risk of infection from spouses. The instrument contained a 14-point knowledge scale on HIV transmission and its prevention. Both instruments were pretested for validity and reliability.

Trained research assistants, with the authors supervising, collected the data among the consenting married women. Before the administration of the questionnaire, verbal informed consent was obtained from the respondents. Confidentiality was ensured as no identifiers were included in the questionnaire. Interviews were conducted away from the hearing distance of other people and during free periods respecting their work schedule. Data collected were stored in a secured place.

\subsection{Data analysis}

Data collected were reviewed on the field at the end of each day for correctness. A coding guide was developed and used in coding the data. The data were entered into the computer for statistical analysis using the SPSS package. Descriptive and inferential statistics were used in the analysis of the data. All statistical tests were carried out at $5 \%$ level of significance. The knowledge scale was assessed by assigning one point to a correct response. No mark was given a wrong response. Scores of 1-5, 6-10 and 11-14 points were classified as poor, fair and good knowledge respectively. The qualitative data was analysed using themes.

\subsection{Ethical consideration}

Prior to entering the research site, permission to carry out the study was obtained from relevant community gate keepers concerned. The nature, purpose and process of the study were explained to the respondents after which verbal informed consent were obtained. Respondents were assured of confidentiality, privacy and anonymity of information provided. It was explained to the respondents that the confidentiality of information shared during the interview would be guaranteed and treated as confidential and private. Necessary steps such as asking for no names and keeping data sources in a secure place were taken to ensure confidentiality. Respondents were continuously reminded of their right to withdraw from the study at any time. 
After each session, the respondents were consulted to ensure that study findings reflected their voices and perceptions.

\subsection{Socio-demographic factors}

\section{Results}

The age of respondents ranged from 16 to 45 years with a mean age of $30.2 \pm 2.9$ years with $46.2 \%$ in the 26-35 year age bracket. More (42.6\%) had primary education as the highest level of education attained, $67.2 \%$ were in monogamous marriages and $70.8 \%$ were traders (Table 1 ).

Table 1 Socio-demographic characteristics of respondents

\begin{tabular}{lcc}
\hline $\begin{array}{l}\text { Socio-demographic } \\
\text { Characteristics of respondents }\end{array}$ & Frequency & Percent (\%) \\
\hline Age: & & \\
$16-25$ & 90 & 23.0 \\
$26-35$ & 180 & 46.2 \\
$36-45$ & 120 & 30.8 \\
Total & 390 & 100.0 \\
& & \\
Educational level: & & 42.6 \\
primary & 166 & 32.3 \\
senior secondary & 126 & 15.1 \\
junior secondary & 55 & 5.9 \\
higher education (University/polytechnic etc) & 23 & 5.1 \\
no formal education $\quad$ Total & 20 & 100.0 \\
\end{tabular}

\subsection{Respondents' awareness and knowledge of HIV and AIDS}

All the 390(100\%) respondents had heard about HIV and AIDS and sources of information were the radio $(86.2 \%)$; television $(69.0 \%)$; health worker $(51.5 \%)$; friends $(32.3 \%)$ and newspaper $(13.1 \%)$. The most commonly mentioned mode of HIV transmission was sexual intercourse $(98.2 \%)$. Other means of HIV transmission mentioned included sharing of unsterilized sharp objects or instruments (82.1\%), blood transfusion (46.7\%), mother to child transmission (30\%) and sharing of cutleries and sharing of toilet (1.5\%). Methods of prevention known by respondents were mutual faithfulness between spouses $(71.3 \%)$, avoidance of sharing sharp objects and instruments $(61.3 \%)$, use of condom $(42.1 \%)$ and avoidance of taking unscreened blood $(37.7 \%)$. Loss of body weight $(70.3 \%)$ topped the list of signs and symptoms of HIV infection known by respondents followed by skin infections (29.7\%), prolonged diarrhoea (14.6\%) and tuberculosis $(12.6 \%)$. Twenty six percent of respondents did not know any signs or symptoms of infection. Sixteen percent of respondents were of the opinion that AIDS could be cured medically (8.7\%), spiritually (5.6\%) and through the use of herbs $(0.3 \%)$. A large percentage of respondents $(60.8 \%)$ believed that the worst thing that could happen to a person with HIV was death, $25.9 \%$ mentioned loss of body weight, $23.6 \%$ mentioned ill health, $3.8 \%$ stigmatization while $5.1 \%$ did not know the worst that could happen to a person with HIV.

The overall mean knowledge score on a 14-point knowledge scale was 7.31 22.6 . Knowledge was significantly higher among respondents aged 26-35 years (7.5 \pm 2.9$)$ and those aged 36-45 years (7.4 \pm 2.9$)$ compared with those in age group 16-25 years (6.7 \pm 2.9 ). Mean knowledge score for those with tertiary education was significantly higher $(8.8 \pm 2.9)$ compared with those with senior secondary $(8.0 \pm 2.9)$, junior secondary (6.9 \pm 2.9 ), primary education $(6.7 \pm 2.6)$ and no formal education $6.7 \pm 2.3$. Type of marriage was found not to influence knowledge of HIV/AIDS.

\subsection{Perception of risk towards contracting HIV}

Three hundred and thirty-one $(84.9 \%)$ respondents perceived HIV infection as very serious; $8.0 \%$ perceived it to be somewhat serious; $5.6 \%$ were not certain about the seriousness of the infection and $1.5 \%$ were of the perception that it was not at all serious. Categories of people perceived to be at risk of infection included sex workers $(91.0 \%)$, single men $(83.3 \%)$; married men $(82.3 \%)$; single women $(82.1 \%)$; married women (79.5\%); drivers (79.0\%); health workers $(72.3 \%)$ and young children $(64.4 \%)$.

Majority of respondents $(95.4 \%)$ were of the opinion that married women were at risk of HIV infection while $44.0 \%$ believed that women's primary source of risk were their spouses. Of the $95.4 \%$ who felt married women were at risk only $37(10.0 \%)$ perceived themselves to be at a high personal risk of contracting HIV from their spouses (Fig.1). 


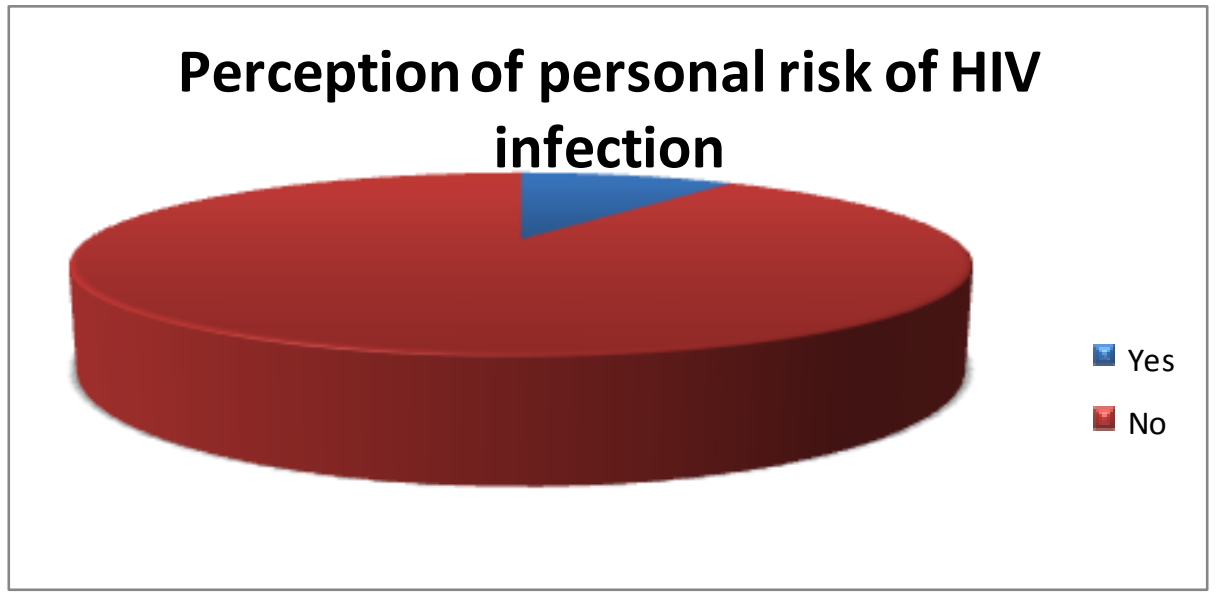

Figure 1. Respondents' perception of personal risk of HIV infection

Main reasons adduced for perception of personal vulnerability were spouses' unfaithfulness $(64.9 \%)$ and polygyny (27.0\%) (Fig. 2). Personal protection methods employed by respondents included use of condom $(68.2 \%)$, abstinence $(50.0 \%)$, separation $(20.5 \%)$, spousal communication $(18.2 \%)$ and use of traditional methods $(4.5 \%)$.

Fifty five percent of respondents reported ever discussing sexual issues with their spouses. Of these 46.4\% had ever discussed issues relating to HIV and AIDS. Thirty-seven percent of respondents reported that their spouses had expressed a willingness to discuss such issues while 33.8\% reported that their spouses had ever initiated discussion on issues relating to HIV and AIDS with them.

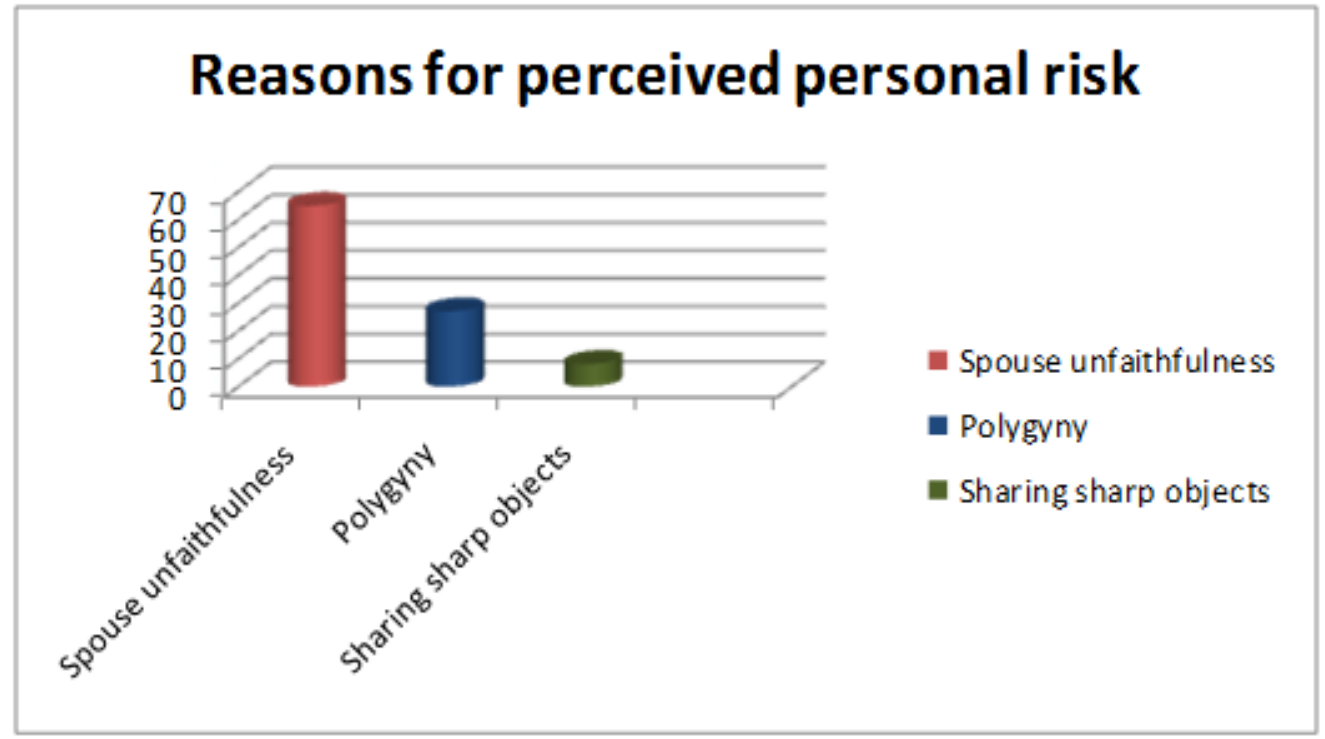

Figure 1: Respondents' reasons for personal perceived risk of HIV infection

\subsection{Socio-Cultural factors that can facilitate transmission of HIV between spouses}

Respondents were asked to list socio-cultural factors that they perceived to predispose married women to HIV infection from their spouses. Practices listed were polygyny (72.2\%); permissive sexual behaviour for men $(51.5 \%)$, spouse-sharing $(38.5 \%)$; widow-cleansing $(25.1 \%)$, negative disposition to protected sexual intercourse within marriage 29(7.4\%), widow-inheritance $(2.3 \%)$; early marriage (2.0\%) and female circumcision $4(1.0 \%)$.

\subsection{Proffered Preventive Strategies against HIV infection in marriage}

Respondents were asked to list preventive strategies acceptable within the marital union. To these, respondents listed mutual faithfulness $(82.0 \%)$, use of condoms $(8.5 \%)$, use of traditional methods $(6.7 \%)$, spousal communication $(5.9 \%)$, voluntary counseling and testing $(2.1 \%)$ and prayers $(1.0 \%)$.

Focus group discussion participants in addition to mentioning the use of condom and spousal communication felt that "the best method of preventing HIV was satisfying one's spouse sexually so he doesn't 
have any reason to indulge in extra-marital affairs; others were of the view that "the best method was to provide one's spouse with condoms that he can use when indulging in extra-marital affairs".

\section{Discussion}

The awareness of HIV/AIDS among the study population was high and sources of information reported by this study corroborate those documented by an earlier study by Pallikadavath, Sreedharan and Stone [11] among married Indian women studied. This suggests the effectiveness of the media in the dissemination of health information as documented by Liskin [12]. The disconnect between the high level of awareness and knowledge corroborates an earlier assertion that people's overall knowledge about the nature of HIV and AIDS is often low despite their high level of awareness of the disease condition [13].

This study found that the mid and older age group women had higher mean scores than younger women, a finding that refutes the assumption that the younger women who are more dynamic ought to be more knowledgeable. This affirms findings that linked the soaring HIV rates among younger married women partly to a lack of adequate knowledge about HIV and AIDS [14]. The higher knowledge level documented among the older age groups may be related to the fact that older women, because of their stage in life, have more opportunities to interact with people outside of their family, have more access to information about HIV /AIDS and are more likely to have self confidence to ask questions and discuss issues relating to sex and HIV more freely than their younger counterparts.

The positive association between respondents' educational attainment and knowledge of HIV/AIDS confirms earlier documentations $[15,16]$. Formal education has been documented to have the capacity to influence vulnerability by exposing girls to HIV and AIDS education, which helps prevent HIV; provision of psychosocial benefits for young women, helping them to build their self-esteem and capacity to act on HIV prevention messages; better economic prospects, which in turn lead to lifestyle changes that can influence HIV vulnerability; power within sexual relationships and the social and sexual networks of the girl child [17].

Findings from this study did not show any significant association between risk perception and knowledge about HIV. This is contrary to the AIDS risk reduction model that states that knowledge is a prerequisite to recognizing risky behaviour and taking action to change it [18]. The relationship between perception of risk and sexual behaviour is complex and poorly understood [19]. Studies conducted on the influence of knowledge on perception of risk and adoption of safer sexual practices has reported mixed results. Some have reported that an individual's knowledge of HIV and accurate assessment of their own risk seem to be among the key factors in the adoption of safer sexual practices [20]. Other studies have reported a lack of association between HIV knowledge and sexual behaviour [21]. However some studies have reported that a possible reason for this discrepancy is that women may not apply their knowledge of disease transmission to assess their risk level every time they engage in sexual activity and that women are more reluctant than men to report their self-assessment of risk [22]. This report lends support to the findings of this present study.

Despite the perception of many respondents in this study that married women are at risk of contracting HIV from their spouses, only $10.0 \%$ perceived themselves to be at personal risk which is $2 \%$ less than the $12 \%$ reported by Chatteriee and Hosain [23]. This finding may be due to the fact that many of them see marriage as a safe haven from the infection and see their partners as not infected. This opinion is consistent with those of married women in India and Thailand where the married women studied felt that they were not at risk because they knew the men and their history and therefore trusted them not to be infected [23,24]. Unfortunately wives of men who engage in high risk behaviours often have inadequate knowledge of their husband's sexual activities outside marriage and hence, do not perceive themselves at risk [25] and marital sex have been documented to be the single greatest risk for HIV infection for a growing number of women around the world [26].

When asked what preventive measures they considered appropriate for use within marriage, the majority of respondents mentioned mutual faithfulness between spouses with a few listing use of condom, spousal communication and voluntary counselling and testing and prayers. This trend may not be unconnected with the socio-cultural barriers that prevent discussion of safer sex behaviours between husband and wife [27]. Attempts at negotiating condom use in marriage may be misinterpreted as an allegation of infidelity and could lead to violence $[28,29]$. Furthermore, the social expectation of women as child bearers and rearers is a potential barrier to the use of protective methods as it inhibits the women's ability to fulfill this reproductive role.

Findings from this study has shown that it may be expedient to involve religious leaders and traditional healers in the sensitization programme as respondents believe in the potency of prayers and traditional methods in the prevention of HIV infection. Religious leaders and traditional healers form an important gateway to reaching people with health-related information. Religious leaders have been observed to have a significant role to play in the adoption of healthful behaviour by their congregation and this can be explored for prevention of HIV. 
The results of this study have far reaching implications for planning, designing, implementing and evaluating HIV prevention and education programmes for married women in Nigeria. One of the key implications of the study is the need for culturally sensitive programmes at the family level with men as key stakeholders. Educational activities targeting married women is uncommon compared with education targeting the general population. Community based women and men groups provide a golden opportunity for doing this. Effective, efficient and cheap educational opportunities such as the community town meetings for reaching married women in the community should be used to educate women.

\section{Conclusion}

This study revealed that many married women do not consider themselves vulnerable to HIV infection from their spouses hence the need for public enlightenment to raise their awareness on vulnerability to infection. Also most HIV prevention programmes focus on strategies like abstinence, mutual fidelity and use of condom. These are strategies that are difficult for women to implement within marriage. Since marriage and motherhood are important in the Nigerian cultural context, new evidence-based strategies that can make intercourse within marriage safer for women should be promoted. One of such strategies is spousal communication. There is a need to sensitize women in marital relationships on the importance of spousal communication as a means of keeping the risk of HIV transmission among spouses at the lowest ebb. Women should be trained in the art of culturally acceptable communication skills while involving men as key stakeholders.

\section{Acknowledgements}

The authors will like to thank all respondents who participated in the study.

\section{REFERENCES}

[1] UNAIDS (The Joint United Nations Programme on HIV/AIDS) Regional Facts sheets 2012. Retrieved on February 14, 2013 from http://www.unaids.org/en/media/unaids/contentassets/documents/epidemiology/2012/gr2012/2012_FS_regional_ssa_en.pdf

[2] C Underwood, A. Kapunigio, R. Tembo, P. Chabwela, W. Glass \& B. Howard. Understanding the dynamics of HIV/AIDS and family planning at the community level in Zambia, 2006. Retrieved on February 14, 2013 from www.nac.org.zm/index.php/research/coc_view/07-understanding-dynmics-of-hivaids-and-family-planning-at-the-community-levelin-zambia?tmpl=format=raw

[3] K.L. Dunkle, R.K. Jewkes, H.C. Brown, G.E.Gray, J.A. Mclntryre \& S.D. Harlow. "Gender-based violence, relationship, power and risk of HIV infection in women attending antenatal clinics in South Africa." Lancet, 2004, 363(9419): 1415-21.

[4] UNFPA. The New York Call to Commitment: Linking HIV/AIDS and sexual and reproductive Health 2004. Retrieved on February 14, 2013 from: UNFPA website: www.unfpa.org/icpd/10/docs/hiv-aids-rh-call-commitment.doc

[5] S. Sippel. The fidelity fallacy: The Link between HIV Infection and Marriage, 2007. Retrieved on February 12, 2013 from www.americanprogress.org/issues/women/news/2007/08/09/3400/the-fidelity-fallacy-the-link-between-hiv-infection-and-marriage/ UNAIDS (Joint United Nations Program on HIV/AIDS) 2004. 2004 Report on Global AIDS Epidemic. Geneva: UNAIDS

[7] USAID. Family Planning and HIV integration: Technical Guidance for USAID-Supported Field Programs 2003. Retrieved on February 7, 2013 from www.usaid.gov/our_work/global_health/pop/publication/docs/fphiv.pdf

[8] NACA (National Agency for Control of AIDS) 2011 Factsheet 2011: Women, Girls and HIV in Nigeria. Retrieved on February 10, 2013 from http://naca.gov.ng/content/view/419/lang,en/

[9] International Institute for Population Sciences (IIPS) and Population Council, 2007. Youth in India: Situation and Needs, 20062007, Facts Sheet: Maharashtra, Mumbai: IIPS

[10] V. Mishra, B.A. Simona, H. Ruthavuth \& V. Martin . "Why Do So Many HIV-Discordant Couples in Sub-Saharan Africa Have Female Partners Infected, Not Male Partners?” 2007Paper presented at the HIV/AIDS Implementers' Meeting, Kigali, 20-22 June.

[11] S. Pallikadavath, C. Sreedharan, \& C.J. Stone. Sources of AIDS Awareness among women in India. AIDS Care, 2006, 18:44-48.

[12] D. Linskin. Health education and the media. Health Promotion International 1990, 15 (3): 237-248.

[13] M.D. Isibor \& A.J. Ajuwon. Journalists' knowledge of AIDS and attitudes to people living with HIV in Ibadan, Nigeria. African Journal of Reproductive Health, 2004, 8(2): 101-110.

[14] N. Sadik. 2008 Disproportionate rate of HIV among young married women. Speech delivered at the $8^{\text {th }}$ International Congress on AIDS in Asia and the Pacific (ICAAP). Retrieved on February 14, 2013 from www.ipsnews.net/2007/08/health-asia-hiv-aids-takeon-a -woman39s-face/

[15] National Population Commission (NPC) [Nigeria] and ICF Macro. 2009. Nigeria Demographic and Health Survey2008. Abuja, Nigeria: National Population Commission and ICF Macro

[16] O.O.C. Lawoyin. Findings from a HIV/AIDS programme for young women in two Nigerian cities: A short report. African Journal of Reproductive Health, 2007, 11(2): 90-97.

[17] J. Hargreaves \& T. Boler. Girl power: the impact of girl's education on HIV and sexual behaviour. Action Aid International, 2006

[18] J.A. Catania, S.M. Kegels \& T.J. Coates. Towards an understanding of risk behavior on AIDS risk reduction model (ARRM), Health Education Quarterly, 1990, 17(1): 53-72.

[19] J.R. Glynn, M. Carael, B. Auvert, M. Kahindo, J. Chege, R. Musonda, F. Kaona \& A. Buvé. Why do young women have a much higher prevalence of HIV than young men? A study in Kisumu, Kenya and Ndola, Zambia. AIDS 2001; 15 Suppl 4:S51-60.

[20] UNAIDS Report on the global AIDS Epidemic 2010/ Retrieved on February 12, 2013 from http://www.unaids.org/documents/20101123_globalreport_em.pdf

[21] C. Lindan. Knowledge attitudes and perceived risk among urban Rwandan women: Relationship to HIV infection and behavior change. AIDS, 1991, 5(8); 993-1002.

[22] C. Nyoni. Socio-cultural factors and practices that impede upon behavioral change of Zimbabwean women in an era of HIV/AIDS A doctoral thesis submitted to the Department of Sociology, University of South Africa 2009. Retrieved February 2, 2013 from http://uir.unisa.ac.za/bitstream/handle/10500/2323/theseis.pdf? sequence=1 
[23] N. Chatteriee \& G.M. Hosain. Perceptions of risk and behaviour change for prevention of HIV among married women in Mumbai, India. Journal of Health, Population and Nutrition 2006, 24(1): 81-8

[24] W. Navarage \& J. Oehler J. Sexual risk among women at reproductive age, Bangkok, Thailand. Journal Public Health, 2008, 38(2):148-164

[25] S. Newmann, P. Sarin \& N. Kumarasamy. Marriage, monogamy and HIV: A profile of HIV infected women in South India. International Journal of STD\&AIDS, 2000, 11: 250-253

[26] J.S. Hirsch, S. Meneses, B. Thompson, M. Negroni, B. Pelcastre \& C. del Rio. The inevitability of Infidelity: Sexual Reputation, social geographies, and marital HIV Risk in rural Mexico. American Journal of Public Health, 2007, 97(6): 986-996

[27] R.H. Steinbrook. Women in India- a complex epidemic. New English Journal of Medicine, 2001, 356: $1089-1093$.

[28] V.F. Go, S.C. Johnson, M.E. Bentley, S. Sivaram, A.K. Srikrishnan, D.D. Celentano \& S. Solomon. Crossing the threshold: engendered definitions of socially acceptable domestic violence in Chennai, India. Culture, Health \& Sexuality, 2003, 5: 393-408

[29] D.S. Varma, P.S. Chandra, C. Callahan, W. Reich \& L.B. Cottler. Perceptions of HIV risk among monogamous wives of alcoholic men in South India. Journal of Women's Health, 2010, 19 (4):815-821 